\title{
Auxerre, abbaye cistercienne des Isles. Démolition des derniers vestiges hors sol (printemps 2004)
}

\section{Sylvain Aumard}

\section{(2) OpenEdition \\ 1 Journals}

\section{Édition électronique}

URL : https://journals.openedition.org/cem/649

DOI : $10.4000 /$ cem.649

ISSN : 1954-3093

Éditeur

Centre d'études médiévales Saint-Germain d'Auxerre

\section{Édition imprimée}

Date de publication : 15 août 2005

ISSN : 1623-5770

\section{Référence électronique}

Sylvain Aumard, «Auxerre, abbaye cistercienne des Isles. Démolition des derniers vestiges hors sol (printemps 2004) », Bulletin du centre d'études médiévales d'Auxerre / BUCEMA [En ligne], 9 | 2005, mis en ligne le 13 octobre 2006, consulté le 22 septembre 2022. URL : http://journals.openedition.org/cem/ 649 ; DOI : https://doi.org/10.4000/cem.649

Ce document a été généré automatiquement le 22 septembre 2022.

\section{(c) (i) (2) (2)}

Creative Commons - Attribution - Pas d'Utilisation Commerciale - Partage dans les Mêmes Conditions 4.0 International - CC BY-NC-SA 4.0

https://creativecommons.org/licenses/by-nc-sa/4.0/ 


\title{
Auxerre, abbaye cistercienne des Isles. Démolition des derniers vestiges hors sol (printemps 2004)
}

\author{
Sylvain Aumard
}

1 Localisé dans l'ancien camp militaire du CIGA Centre ${ }^{1}$, le site de l'ancienne abbaye des cisterciennes de Notre-Dame des Isles est parfaitement connu par les archives, les recherches historiques et les découvertes anciennes ${ }^{2}$. Cette communauté a d'abord été établie à Saint-Georges-sur-Baulche en 1219. Dix ans après, elle bénéficie d'une importante donation par la comtesse Mathilde d'Auxerre pour s'installer plus confortablement à Orgelaine-sur-Yonne où elle construit rapidement un nouveau couvent (l'abbatiale est consacrée en 1233). Au cours du XVII e siècle, un nouveau transfert a lieu en ville et l'établissement des Isles est affecté en unité agricole dont témoignait une grange encore en élévation il y a peu. Des blasons sculptés remployés dans un des murs pignons de ce bâtiment ont fait l'objet d'une protection au titre des objets mobiliers et ont été récupérés au cours de la démolition par le Musée d'Auxerre. Sans caractère historique évident, l'immeuble ne bénéficiait d'aucune protection et n'a jamais fait l'objet d'une étude de bâti. Au cours de visites sur place, il était aisé de remarquer un certain nombre de remplois d'origine médiévale dans les constructions (fragments de moulures, colonnettes...). Dans le cadre du plan de formation du Centre consacré en 2003-2004 au maniement du théodolite laser récemment acquis, ce bâtiment a servi de "lieu d'exercice" et un plan partiel a ainsi été levé ${ }^{3}$. Un croquis très sommaire de la charpente levé au cours de la veille de la démolition, complète désormais une documentation bien maigre.

Cette grange respectait l'orientation des bâtiments claustraux perceptibles sur une photographie aérienne des années cinquante ${ }^{4}$; elle avait donc de fortes chances de réutiliser des murs de l'abbaye et de comporter des remplois d'architecture.

3 La DRAC n'ayant pu imposer une étude des élévations, le nouveau propriétaire (société Ternant) et les entreprises de démolition nous ont laissé faire quelques rapides observations, certes bien trop frustres vu l'histoire du site. Comme nous le pressentions 
aisément, la démolition de ce bâtiment qui ne présentait a priori que très peu d'intérêt, a mis au jour de nombreux blocs sculptés de l'époque gothique (XIII ${ }^{\mathrm{e}}$ ou $\mathrm{XIV}^{\mathrm{e}}$ siècle) vraisemblablement en rapport avec l'architecture de l'abbatiale : chapiteaux à feuilles d'eau, fragments de colonnes, bases, etc. Pour le moment, ces éléments sont conservés par le propriétaire, mais aucun moyen ne permet actuellement de les étudier et de les restituer au public, ni même de s'assurer de leur pérennité dans le temps par une conservation adéquate.

4 Une dizaine de tuiles a également été récupérée (petit format à crochet) et cinq rondelles ont pu être prélevées sur les bois de charpentes grâce à l'aimable concours de Benoît Dulion, charpentier à Ancy-le-Franc. Le diagnostic établi par ce dernier a confirmé le nôtre au sujet de l'existence de remplois dans la charpente démolie et a établi, en outre, que les murs gouttereaux en maçonnerie ne faisaient probablement pas partie de l'état d'origine du bâtiment. La charpente de ce dernier était peut-être, en effet, entièrement appuyée sur des poteaux disposés en travées, tels qu'on peut l'observer sur certains modèles traditionnels encore visibles de nos jours.

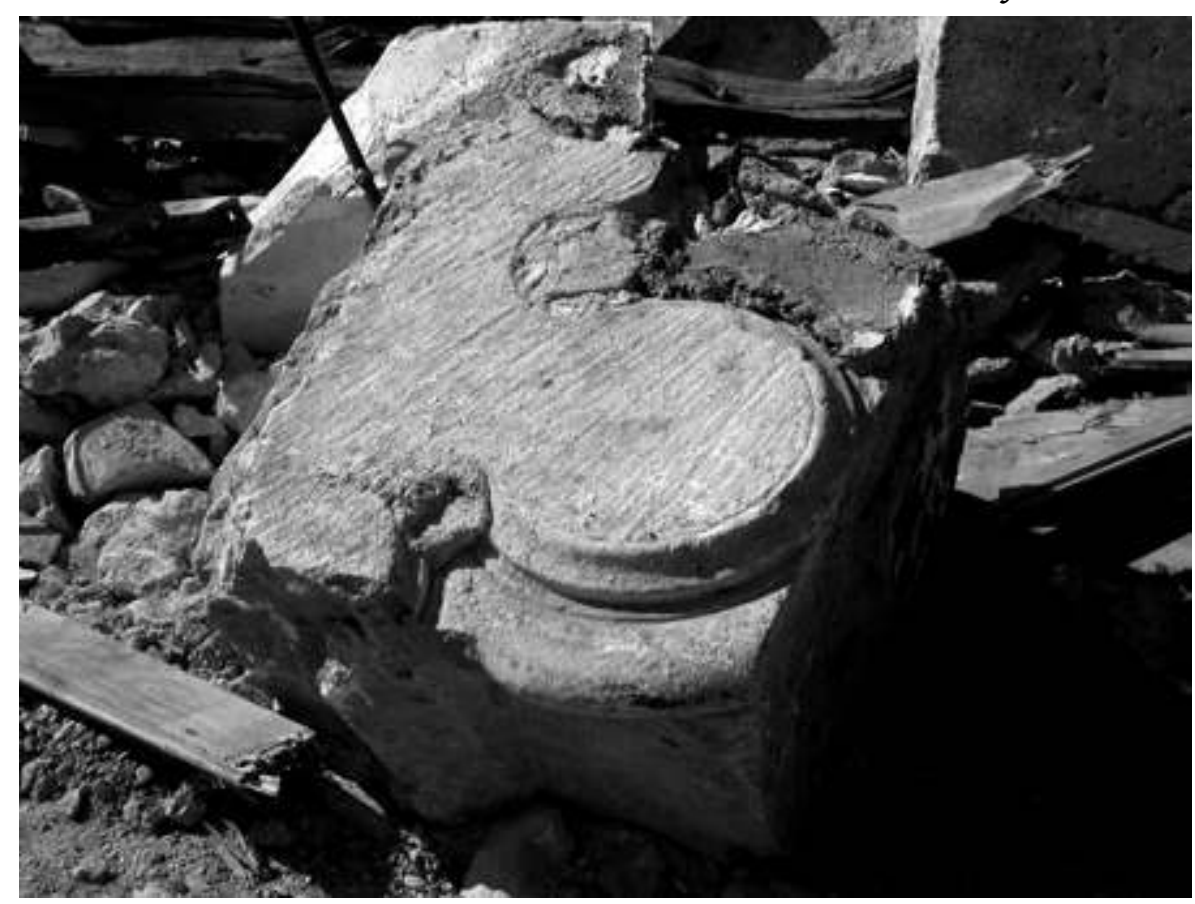




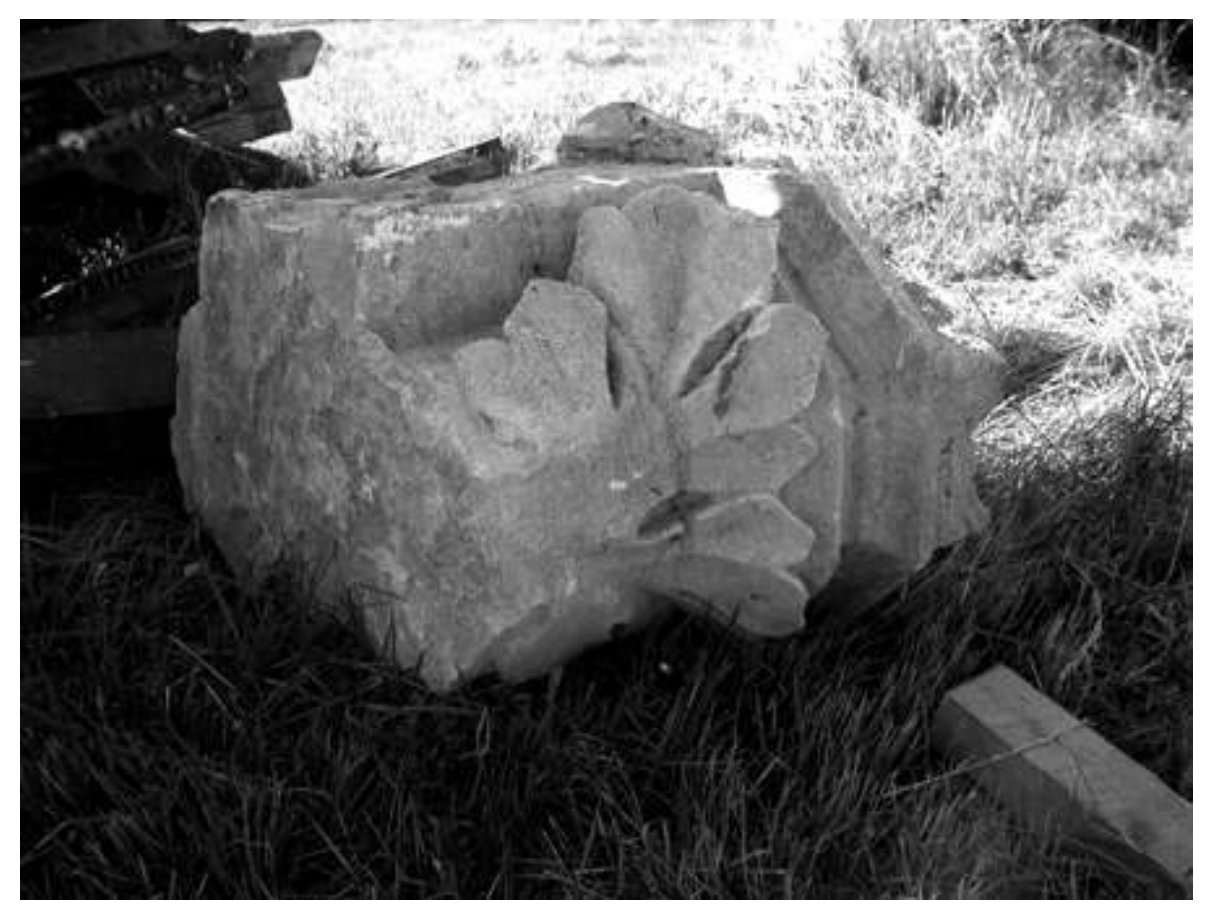

Auxerre, abbaye cistercienne des Isles. Base et chapiteau (clichés CEM).

\section{NOTES DE FIN}

1. Centre d'Instruction des Gendarmes Auxiliaires (Ministère de la défense).

2. Une contribution sous la plume de M.-E. HENNEAU dans le catalogue d'exposition Les cisterciens dans l'Yonne (sous la dir. de T. KINDER), 1999, p. 163-171 constitue à ce jour la synthèse la plus aboutie. Au courant du projet de cession des terrains par le Ministère des armées, nous avons pris l'initiative, en 2001, de compléter les données de la DRAC (SRA) sur la localisation du site par de nouvelles recherches (S. AUMARD, Les campagnes médiévales de l'Auxerrois, Rapport de prospection-inventaire inédit, CEM, DRAC, 2001). 3. Ce plan comporte des défauts inhérents à son contexte de réalisation (formation) et n'a pu être corrigé avant la démolition du bâti. Toutefois, on possède désormais un plan inédit des trois quarts de l'espace de cette grange, selon un précision acceptable. 4. Photographie conservée au Service départemental des Antiquités et Objets d'Art (Conseil général de l'Yonne à Auxerre) et aimablement signalée par B. Clert responsable de ce service.

\section{INDEX}

Index géographique : France/Auxerre

Mots-clés : abbaye cistercienne, Notre-Dame des Isles d'Auxerre 